\title{
Molecular Characterization and Evolutionary Analysis of Potential Fusarium Resistant Genes for Crop Improvement
}

\author{
Ashok Yadav ${ }^{1 *}$, Usha Kalidindi ${ }^{1}$, Pawan Kumar Jayaswal ${ }^{3}$, \\ Shikha Mittal $^{2}$ and Nepolean Thirunavukkarasu ${ }^{2}$
}
${ }^{1}$ Divison of Fruits and Horticultural Technology, Indian Agricultural Research Institute, New Delhi-110012, India
${ }^{2}$ Division of Genetics, Indian Agricultural Research Institute, New Delhi-110012, India
${ }^{3}$ National Research Centre for Plant Biotechnology, Indian Agricultural Research Institute,
New Delhi-110012, India

*Corresponding author

\section{A B S T R A C T}

Fusarium species cause considerable crop losses worldwide and necessitate an expensive use of chemical pesticides. Resistant genes can be used to improve plant resistance through gene editing and gene silencing strategies. Currently, information on host defences against Fusarium species is limited. Through in-silico tools, identification of genes and understanding of disease resistance mechanism has become possible. In the present study,

\section{Keywords}

Fusarium, Candidate genes, cis-regulatory, Disease resistance protein structure

Article Info

Accepted:

26 January 2018

Available Online:

10 February 2018

a comprehensive in-silico analysis of 65 Fusarium resistance genes belonging to 10 different species was carried out to understand the physiochemical properties, secondary and tertiary protein structures, protein binding sites, phylogenetic relationship, cisregulatory elements and protein motifs. Five genes on the basis of their stability have been selected for 3D structure prediction using Phyre 2 server. These structures were evaluated and validated using Verify-3D, PROCHECK and Ramachandran plot. The Z score predicted by ProSA-web tool indicated reliability of the 3D structures while above $97 \%$ of the region falls in allowed region of Ramachandran plot. The distribution pattern in five genes for binding site is high, while hydrophobicity is very low to low. The most commonly occurring motifs among Fusarium resistance genes were motif-3 and motif-1, whereas cis-regulatory elements were TC-rich repeats, Box-W1, EIRE, AT-rich sequence, CGTCA-motif and TGACG-motif. The results of cis-acting regulatory elements and motif analysis revealed that they are actively involved in the expression and regulation of Fusarium resistance genes during cellular development and under biotic stress conditions in different plant species. In-silico analysis revealed the homology of Fusarium resistance genes and will be helpful to develop molecular markers or gene specific markers to overcome the Fusarium related biotic stresses.

\section{Introduction}

Fusarium species are widely distributed in soil, subterranean and aerial plant parts, plant debris, and other organic substrates (Nelson et al., 1994). More than 50 species of Fusarium have been identified, but a few cause destructive diseases like blights of 
cereal crops, wilts and rots of important fruit and vegetable crops and disorders of many ornamental plants resulting in 30 to $70 \%$ yield losses(Bentley et al., 2006; Bockus et al., 2007; Saremi et al., 2010; Chakraborty and Newton, 2011). Very little information is available regarding host defences against Fusarium species. Fusarium resistance genes are highly polymorphic and have wide recognition specificities and are commonly clustered in the genome. These genes originated through gene duplication are continuously evolving through unequal exchange and constant selection pressure by pathogen evolution (Joshi and Nayak, 2013). Conventional breeding approaches to develop plant resistance to Fusarium are slow due to a highly complex mechanism. Biotechnology serves as a powerful tool for manipulating disease resistance in crop plants through QTL mapping and genetic transformation with the aim of increasing crop productivity in the affected areas.

To identify homologs in resistance genes, similarity searching plays a crucial role because the sequences which are similar can be treated as homologous as they could have a same ancestor. Cis regulatory element (CRE) is region of non-coding DNA which regulates the transcription of nearby genes. Cisregulatory module is a stretch of DNA, usually 100-1000 DNA base pairs in length(Davidson, 2006), where a number of transcription factors can bind and regulate expression of nearby genes and regulate their transcription rates. CREs are vital components of genetic regulatory networks, which in turn control morphogenesis, the development of anatomy and other aspects of developmental biology (Fiedler and Rehmsmeier, 2006; Ibraheem et al., 2010; Hernandez-Garcia and Finer, 2014).The plant gene or resistance gene sequences through phylogenetic analysis can provide the most meaningful insights to researchers in different diverse fields, including ecology, molecular biology and physiology. Phylogenetic analysis framework resulted in evolution of various morphological and chemical traits (Ronsted et al., 2012), production of secondary metabolites (Agrawal and Fishbein 2008; Agrawal et al., 2009; Van den Bergh, 2016) along with various complex pathways such as $\mathrm{N}_{2}$-fixing symbioses (Werner et al., 2014), chemical defence mechanisms (Agrawal, 2011), and mustard oil production (Van den Bergh, 2016).For the evolutionary synthetic biology, construction of phylogenetic trees would serve as the foundation for better understanding the evolution of cellular pathways, macromolecular machines and other emergent properties of early life (Gaucher et al., 2010). Hence, phylogenetic tree analysis would help guide organisms in forming their unique biological traits by regulating the composition of structural sequence elements.

The transcriptional regulation of genes is governed by the cis-elements during plant growth and development and under abiotic stress conditions (Nakashima et al., 2009). Cis-regulatory elements are useful in crop improvement for developing stable resistance genes that are transcribed in predictable ways and can be maintained during the natural processes of reproduction of the plant. Most of the CRE's are related to "Light responsive" followed by "Hormone Responsive", "abiotic stress", "biotic stress", "binding" and "transcription process". Currently, due to availability of comprehensive modern protein sequence databases, $80 \%$ or more of metagenomic sequence have similarity in protein sequences. Similarity searching tools that provide reliable results are BLAST, PSIBLAST, SSEARCH, FASTA and the HMMER3 programs (Johnson et al., 2010).Accurate sequence alignments of resistance genes can be built after the homolog's search through multiple sequence alignments, which can serve as a base for 
phenotype prediction and evolutionary analysis. Several reports on in-silico analysis indicate that this study is a very promising approach (Dutt, et al., 2010; Mallikarjuna et al., 2016; Bhati et al., 2016; Azam et al., 2017). In the present study, a comprehensive in-silico analysis of Fusarium resistant genes was carried out by working on multiple sequence alignment analysis, construction and visualisation of phylogenetic trees, motif prediction and physicochemical analysis of protein sequences. The information generated will be useful to develop resistant genotypes in different crops through development of molecular markers or gene specific markers.

\section{Materials and Methods}

\section{Sequence retrieval of Fusarium resistance genes}

The nucleotide and protein sequences of Fusarium resistance genes of banana (Musa acuminata), tobacco (Nicotiana alata), petunia (Petunia $x$ hybrid), lilium (Lilium regale), onion (Allium cepa), soyabean (Glycine max), rice (Oryza sativa), Arabidopsis (Arabidopsis thaliana), tomato (Solanum lycopersicon) and melon (Cucumis melo) were collected from NCBI (www.ncbi.nlm.nih.gov) and coding sequences from European Nucleotide Archieve (http://www.ebi.ac.uk/ena/data/view $/<$ accession $>$ ). The selected species comprised the representatives from ten main plant groups such as monocots, dicots and lower plants (Table1). Details of in-silico analysis carried out are shown in Figure 1.

\section{Physico-chemical properties of Fusarium resistance genes}

ProtParam, a protein analysis tool was used for identification of the physicochemical properties of the proteins (http://www.expasy. org/tools/protparam.html). Physiochemical properties including molecular weight, theoretical pI, grand average of hydropathicity
(GRAVY) and instability index were computed using protein sequences. In ProtParam, the average isotopic masses of amino acids and the average isotopic mass of one water molecule were added to get the molecular weight of provided protein. The $\mathrm{pI}$ of protein is the $\mathrm{pH}$ at which the protein does not carry a net-charge and its value is obtained by the number of protonatable and deprotonatable side chains (Garcia-Moreno, 2009). Protein pI was calculated using pKa values of amino acids. pKa values depend on its side chain and has role in defining the $\mathrm{pH}$ dependent characteristics of a protein. The GRAVY value of a protein or a peptide was calculated by adding the hydropathy values of each amino acid residues and dividing by the number of residues in the sequence or length of the sequence. Positive score indicates a greater hydrophobicity. A protein whose instability index is smaller than 40 were predicted as stable and a value above 40 were predicted as unstable.

\section{Secondary and tertiary structural analysis of protein sequences}

The protein sequences of Fusarium resistance genes were used to build 3-D models by the phyre2 server and were evaluated using Verify-3D from PROCHECK software (Luthy, et al., 1992). Ramchandran plot analysis was done by Rampage. Further validation of protein structures was carried out using ProSA web tool (Wiederstein, and Sippl, 2007; Prajapat et al., 2007).

\section{Protein binding sites and hydrophobicity analysis of protein sequence}

Binding sites and hydrophobicity of five stable Fusarium resistance genes were predicted by phyre 2 server tool and for further visualization of output PDB files was done by Discovery studio 3.5 visualizer tools (Nottensteiner, 2015) 
Conserved domain search and transmembrane prediction

The conserved domains among the five stable proteins were predicted through the CDSearch tool from NCBI's interface via RPSBLAST (Marchler et al., 2014). Transmembrane helix was predicted through TMHMM Server (Trans-membrane Helices Hidden Markov Model (Krogh et al., 2001) and visualization of trans-membrane helix was done by Protter tool (Omasits et al., 2013).

Multiple sequence alignment analysis, construction and visualisation of phylogenetic trees

Multiple sequence alignment of the Fusarium resistance genes was carried out using CLUSTALW (http://www.genome.jp/tools/ clustalw/). The aligned sequences were subjected to the MEGA software for construction of phylogenetic tree using the NJ algorithm (Tamura et al., 2013).

The Poisson correction robustness of clustering was checked by bootstrapping of 1000 replicates. Bootstrapping was used to evaluate the degree of support for a particular grouping pattern in the Phylogenetic tree. The visualization of the Phylogenetic tree was done by using Fig tree. The evolutionary distances were computed using the Composite Likelihood method (Gao and Song, 2010) and expressed as number of base substitutions per site.

\section{Motif prediction}

Protein sequences of Fusarium resistance genes were analysed through MEME software and the Motif Alignment and Search Tool (MAST) (http://meme.sdsc.edu/meme/website /intro. html) for motif prediction. Consensus sequences were depicted using the WebLogo version 2.8.2 (http://weblogo.berkeley.edu/).

\section{Cis-regulatory element predictions}

To find out the cis-regulatory elements, $1 \mathrm{~kb}$ upstream sequence of all genes was retrieved from PhytozomeBiomart. The resistance gene sequences were searched against CRE's in the Plant CARE database, using the search for care program (Lescot et al., 2002).

\section{Results and Discussion}

\section{Physicochemical properties of Fusarium resistance genes}

Protein physiochemical analysis indicated that among the 65 protein sequences, molecular weight of the protein ranged from a minimum of 5710.40 (I-2 clone Heamsona) to a maximum of 144827.10 (I-2 complete cds). The pIof protein value ranged from 4.17 to 11.12 (Table 1). Overall, 78.46 per cent fusarium genes were found slightly acidic in nature whereas remaining 21.54 per cent were basic in nature with a $\mathrm{pI}$ of $\geq 8$. The instability index was minimum in CHS-7 and maximum in I-2-clone Heamsona (Table 1). Out of 65 sequences, 32 protein sequences were unstable, whereas 33 protein sequences were stable in nature. The grand average of hydropathicity (GRAVY) in the 65 Fusarium resistance sequences varied from -0.507 (NBS-16) to 0.898 (CHS-7).

\section{Secondary and tertiary structural analysis of protein sequences}

To analyse secondary and tertiary structures of fusarium proteins, 5 proteins (beta-glucanase, I-2-clone-2942, I-7, chit-42 and NBS-15) were selected from 65 proteins on the basis of their high stability belonging to three plants (Tomato, banana and soya bean)and one fungal species (Trichodarma harzianum). The secondary structure composed of alpha helix, beta stand, disordered and TM helix. The secondary structure analysis suggested that 
alpha helix percentage was highest $(52 \%)$ in NBS-15 gene (banana) while minimum in I-7 (20\%).

The beta strand varied from $10 \%$ (I-2, \& I-7) to $24 \%$ in beta-glucanase whereas disordered percentage varied from 15 to $27 \%$ (Table S1).

The 3-D structure (Fig. 2a) predicts the arrangement of secondary structures as well as their side chains into three-dimensional space. The Ramachandran plot consisted of three regions i.e., favoured region, allowed region and outlier region (Fig. 2b).

The favoured region $(97.4 \%)$ was maximum in Chit-42 followed by beta-glucanase (94.2\%), NBS-15 (85.2\%), I2-Clone-2942 $(84.7 \%)$ and I-7 (76.7 \%) whereas allowed region was highest in I-7 (15.2\%) followed by NBS-15 (9.7 \%), I-2 (8.9\%), Beta-glucanase $(5.8 \%)$ and Chit-42 (2.1\%) (Table S2). The Z score predicted by ProSA-web tool inI-2, I-7, NBS-15, chit-42 and B-glucanase were -7.35, $-7.66,-4.68,-3.30$ and -2.95 respectively (Table S3) and were obtained by X-ray crystallography (light blue) as well as NMR spectroscopy (dark blue) in five stable protein sequences of Fusarium resistance genes (Fig. 2c). Whereas according to Verify-3D, in betaglucanase, $95.08 \%$ residues had 3D-1D profile $>=0.2$ followed by $89.60 \%$ residues in chit -42 and $76.09 \%$ in I-7.

\section{Protein binding sites and hydrophobicity analysis of protein sequence}

Protein binding sites and hydrophobicity level of the five genes i.e. beta-glucanase, I-2clone-2942, I-7, chit-42 and NBS-15 has been represented in the Figure 3. The binding sites, hydrophobicity and hydrophilic nature have been represented by green, brown and blue colour respectively. The distribution pattern in five genes for binding site is high as compared to hydrophobicity which was very low to low.
Conserved domain search and Transmembrane prediction

The conserved domain analysis revealed one conserved domain in each of five stable Fusarium resistance genes except Chit-42 and I-7 which had two domains almost similar in function. Among the genes studied for CDsearch, B-glucanase, I-2-2942 andNBS-15 had Glyco-hydro-1 superfamily, P-loop NTPase superfamily and NB-ARC domain respectively. The two conserved domains in Chit-42 gene were GH-18 chitnase-like and Glyco-18 whereas LRR-RI domain was conserved in gene I-7 (Fig. 4). According to THHM Model, trans-membrane helix was present in extending residues from 907 to 929 of I-7 gene (Fig. 5A), while it was absent in rest of four genes (B-glucanase, chit-42, I-22942 and NBS-15). The trans-membrane is represented by blue colour while signal peptide by red colour (Fig. 5B).

\section{Multiple Sequence Alignment and Phylogenetic Analysis}

Protein sequences of Fusarium resistance genes were used to find out the homologous sequences which served as a benchmark for developing resistance genes for unknown Fusarium related diseases in annual, biennial and perennial horticultural crops. The multiple sequence alignment showed the conserved region in Fusarium resistance genes (Fig. 6). The phylogenetic tree was divided into three main groups, namely A, B, and C (Fig. 7). The group A consist of one gene (I2 clone 2956), whereas group B had six genes (I2 clone 3333, I2 clone 2958, I2 clone 2950, I2 clone 3324, I 2 clone 3336 and I 2 clone 2942) belonging to dicot species, Solanum lycopersicum. The group $\mathrm{C}$ had highest (58 gene) Fusarium resistance genes which were further classified into three different subgroups i.e. $\mathrm{C} 1, \mathrm{C} 2$, and $\mathrm{C} 3$ on the basis of their protein motifs. The subgroup-C1 comprises of 19 genes (tomato 
species) with four conserved motifs (motif-1, 2, 3 and 4) and subgroup-C2, a very complicated subgroup, comprising of 25 genes of 9 different plant species (Arabidopsis, banana, Lilium, melon, onion, rice, soya bean, tobacco and tomato) and one from yeast (Saccharomyces cerevisiae) and one from fungi (Trichoderma harzianum) with no conserved motif, whereas subgroup-C3 consisted of 13 genes belonging to banana with three conserved motifs (motif 1, 3 and 5).

The Fusarium resistance genes presented in group A, showed more similar conserved motif pattern with group B followed by subgroup C1 and C3 (Fig. 7). Subgroup C2 was unique as compared to other groups and subgroups.

\section{Motif prediction}

In-silico motif analysis of 65 Fusarium resistance genes revealed that out of total 65 sequences, only 46 sequences had a p-value less than 0.0001 and E-value less than 10.Overall five significant motifs with minimum and maximum width of 12 and 60 respectively were mined for resistance genes and were designated as motif 1 , motif 2 , motif 3 , motif 4 and motif 5 (Table 2).

Among all the genes studied, motif-3, the most frequently occurred motif was present in 43 genes followed by motif- 1 in 40 genes, motif- 2 in 28 genes, motif-4 in 26 genes and motif-5 in 13 genes (Fig. S1).

The gene NBS-15, chit-42, Lr14-3-3 and betaglucanase had one motif, NBS-16 gene had two motifs, whereas 16 genes had three motifs and 24 genes had four motifs (Fig. S1).

\section{Cis-regulatory elements}

Analysis of 65 resistance genes resulted in 92types of cis-regulatory elements. Among them CAAT-box had maximum (65) frequency (present in all the resistance genes) followed by G-box (54), Skn-1_motif (44), ARE (42), TC-rich repeats (36), CGTCAmotif (36), TGACG-motif (36), circadian (35), Sp1(35), O2-site (34), A-box (33), Box I (33), AAGAA-motif (32), MBS (32), TATA-box (32) and TATCCAT/C-motif (32) (Fig. S2). The functions of different cis-regulatory elements are described in Table 3. According to differences in function, cis-regulatory elements were divided into 11 categories along with unknown function category.

Fusarium resistance genes are highly polymorphic and have wide recognition specificities due to gene duplication, genomic forces (insertion, deletion etc.) and constant selection pressure by pathogen evolution. This leads to slow progress in development of Fusarium disease resistant varieties.

Protein information of Fusarium resistance genes can be used in identification of homologs in different plant genomes, preservation of the genetic code, transmembrane alpha-helices of membrane proteins and also to measure the hydrophobicity of a specific peptide/protein in the sample.

Our study has provided valuable insights regarding multiple sequence alignment analysis, construction and visualisation of phylogenetic trees, motif prediction and physiochemical properties of protein sequences.

Out of 65 Fusarium resistance proteins, 33 protein sequences were stable in nature with pIof protein value ranging from 4.17 to 11.12.Protein $\mathrm{pI}$ is having an important role in finding the $\mathrm{pH}$ dependent characteristics of a protein (Talley and Alexov, 2010). The instability index of the protein sequences describes whether the protein is stable or not. 
Table.1 List of various Fusarium resistance genes and their physico-chemical properties

\begin{tabular}{|c|c|c|c|c|c|c|c|c|}
\hline Fusarium species & Gene source & Gene & GenBankID & Protein length & Mol. Wt. & pI. & I.I. & GRAVY \\
\hline \multirow{4}{*}{ Fusarium oxysporum } & Petunia & PhDef-1 & AF507975.1 & 103 & 11361.4 & 6.54 & 49.77 & 0.265 \\
\hline & Petunia & PhDef1-(2) & HQ694498.1 & 103 & 11349.3 & 6.54 & 47.90 & 0.215 \\
\hline & Petunia & PhDef-2 & AF507976.1 & 101 & 11049.0 & 5.16 & 50.94 & 0.176 \\
\hline & Lilium & Lr14-3-3 & KF362120.1 & 259 & 29301.0 & 4.79 & 49.57 & -0.459 \\
\hline $\begin{array}{l}\text { F. oxysporum f. sp. } \\
\text { vasinfectum }\end{array}$ & Cotton & $\mathrm{NaD}-1$ & AF509566.1 & 105 & 11721.9 & 6.56 & 61.25 & 0.137 \\
\hline \multirow{17}{*}{$\begin{array}{l}\text { Fusarium oxysporum } f . s p . \\
\text { cubense }\end{array}$} & Banana & MusaBAG-1 & KJ636053.1 & 152 & 16834.5 & 9.10 & 42.23 & -0.375 \\
\hline & Banana & NBS-2 & KF034946.1 & 174 & 19426.3 & 5.49 & 43.77 & -0.236 \\
\hline & Banana & NBS-3 & KF034947.1 & 174 & 19353.3 & 5.78 & 45.68 & -0.286 \\
\hline & Banana & NBS-4 & KF034948.1 & 174 & 19478.4 & 5.78 & 48.97 & -0.268 \\
\hline & Banana & NBS-5 & KF034949.1 & 174 & 19620.5 & 6.20 & 55.70 & -0.351 \\
\hline & Banana & NBS-6 & KF034950.1 & 174 & 19537.4 & 5.78 & 55.99 & -0.294 \\
\hline & Banana & NBS-7 & KF034951.1 & 174 & 19601.5 & 5.78 & 51.10 & -0.326 \\
\hline & Banana & NBS-8 & KF034952.1 & 174 & 19569.5 & 5.78 & 56.48 & -0.307 \\
\hline & Banana & NBS-9 & KF034953.1 & 174 & 19510.4 & 5.78 & 57.10 & -0.279 \\
\hline & Banana & NBS-10 & KF034954.1 & 174 & 19537.4 & 5.78 & 55.99 & -0.294 \\
\hline & Banana & NBS-11 & KF034955.1 & 174 & 19537.4 & 5.78 & 55.99 & -0.294 \\
\hline & Banana & NBS-12 & KF034956.1 & 174 & 19537.4 & 5.78 & 55.99 & -0.294 \\
\hline & Banana & NBS-13 & KF034957.1 & 174 & 19537.4 & 5.78 & 55.99 & -0.294 \\
\hline & Banana & NBS-14 & KF034958.1 & 174 & 19569.5 & 5.78 & 56.48 & -0.307 \\
\hline & Banana & NBS-15 & KF034959.1 & 178 & 20113.9 & 6.84 & 39.15 & -0.458 \\
\hline & Banana & NBS-16 & KF034960.1 & 212 & 24338.0 & 7.10 & 47.83 & -0.507 \\
\hline & Yeast & CHS-7 & NM-001179272.1 & 316 & 34898.2 & 5.46 & 23.31 & 0.898 \\
\hline \multirow{3}{*}{$\begin{array}{l}\text { Fusarium oxysporumf. sp. } \\
\text { Cubense race } 1\end{array}$} & Onion & Ace-AMP-1 & AF004946.1 & 132 & 15141.9 & 11.12 & 50.39 & 0.017 \\
\hline & Trichoderma & chit-42 & S78423.1 & 423 & 46056.5 & 7.01 & 23.57 & -0.311 \\
\hline & Soybean & beta1,3-glucanase & AF034106.1 & 246 & 26992.5 & 4.52 & 31.12 & 0.074 \\
\hline $\begin{array}{l}\text { Fusarium oxysporum f. sp. } \\
\text { Cubenserace } 4\end{array}$ & Rice & Tlp & XM-015763091.1 & 177 & 17992.1 & 5.07 & 43.10 & 0.185 \\
\hline $\begin{array}{l}\text { Fusarium oxysporumf.sp. } \\
\text { matthioli (FOM) }\end{array}$ & Arabidopsis & RFO-1 & DQ023268.1 & 749 & 83435.4 & 6.43 & 44.85 & 0.200 \\
\hline \multirow{6}{*}{$\begin{array}{l}\text { Fusarium oxysporumf.sp. } \\
\text { melonis }\end{array}$} & Melon & Fom-2-PI161375 & AY619649.1 & 533 & 61579.9 & 8.45 & 49.13 & -0.214 \\
\hline & Melon & $\begin{array}{l}\text { Fom-2 } \\
\text { (AnanasYokneum }\end{array}$ & AY619648.1 & 533 & 61611.8 & 8.04 & 47.99 & -0.211 \\
\hline & Melon & Fom-2(Vedrantais) & AY619647.1 & 533 & 61611.8 & 8.04 & 47.99 & -0.211 \\
\hline & Melon & Fom-2 (Durango) & AY619646.1 & 533 & 61611.8 & 8.04 & 47.99 & -0.211 \\
\hline & Melon & $\begin{array}{l}\text { Fom- } 2 \text { protein gene } \\
\text { (Partial cds) }\end{array}$ & AY619650.1 & 554 & 63811.1 & 7.29 & 45.64 & -0.231 \\
\hline & Melon & $\begin{array}{l}\text { Fom-2 protein gene } \\
\text { (Complete cds) }\end{array}$ & DQ287965.1 & 1073 & 123571.8 & 7.13 & 43.42 & -0.193 \\
\hline \multirow{30}{*}{$\begin{array}{l}\text { Fusarium oxysporum f. sp. } \\
\text { lycopersici }(\mathrm{Fol}) \text { races } 1,2 \\
\text { and }\end{array}$} & Tomato & I-2 (clone 3318) & DQ205979.1 & 242 & 27159.3 & 7.64 & 32.40 & -0.291 \\
\hline & Tomato & I-2 (clone 2949) & DQ205977.1 & 242 & 27113.3 & 8.32 & 30.89 & -0.240 \\
\hline & Tomato & I-2 (clone 3325) & DQ205976.1 & 242 & 27113.3 & 8.32 & 30.89 & -0.240 \\
\hline & Tomato & I-2 (clone-2950) & DQ205975.1 & 233 & 25999.9 & 6.86 & 28.72 & -0.299 \\
\hline & Tomato & I-2 (clone-3324) & DQ205974.1 & 241 & 27017.0 & 6.43 & 33.51 & -0.299 \\
\hline & Tomato & I-2 (clone-2942) & DQ205973.1 & 238 & 26643.7 & 7.64 & 28.50 & -0.267 \\
\hline & Tomato & I-2 (clone-3333) & DQ205972.1 & 243 & 27315.5 & 7.64 & 32.31 & -0.283 \\
\hline & Tomato & I-2 (clone-2957 & DQ205971.1 & 243 & 27315.5 & 7.64 & 32.31 & -0.283 \\
\hline & Tomato & I-2 (clone-3323) & DQ205970.1 & 243 & 27401.6 & 7.64 & 31.31 & -0.300 \\
\hline & Tomato & I-2 (clone-3335) & DQ205969.1 & 243 & 27368.5 & 8.41 & 33.65 & -0.312 \\
\hline & Tomato & I-2 (clone-2961) & DQ205968.1 & 243 & 26650.7 & 8.64 & 29.18 & -0.239 \\
\hline & Tomato & I-2 clone- 2956 & DQ205967.1 & 243 & 27315.5 & 7.64 & 32.31 & -0.283 \\
\hline & Tomato & I-2 (clone-2953) & DQ205966.1 & 242 & 27353.2 & 4.97 & 32.28 & -0.331 \\
\hline & Tomato & I-2 (clone-2944) & DQ205965.1 & 230 & 26076.8 & 5.03 & 32.47 & -0.330 \\
\hline & Tomato & I-2 (clone-3336) & DQ205964.1 & 243 & 27285.4 & 7.64 & 29.05 & -0.281 \\
\hline & Tomato & I-2 (clone-2962) & DQ205963.1 & 242 & 27413.2 & 4.97 & 30.47 & -0.347 \\
\hline & Tomato & I-2 (clone-2947) & DQ205962.1 & 236 & 26328.3 & 8.32 & 26.29 & -0.240 \\
\hline & Tomato & I-2 (clone-2954) & DQ205961.1 & 242 & 27353.2 & 4.97 & 32.28 & -0.331 \\
\hline & Tomato & I-2 (clone-3326) & DQ205959.1 & 243 & 27297.4 & 7.64 & 32.62 & -0.272 \\
\hline & Tomato & I-2-(clone-2943) & DQ205958.1 & 242 & 27111.4 & 8.32 & 30.01 & -0.258 \\
\hline & Tomato & I-2 (clone-3337) & DQ205957.1 & 243 & 27315.5 & 7.64 & 32.31 & -0.283 \\
\hline & Tomato & I-2 (clone-2948) & DQ205956.1 & 242 & 27327.1 & 4.97 & 33.08 & -0.350 \\
\hline & Tomato & I-2 (clone-3332) & DQ205955.1 & 243 & 27301.4 & 7.64 & 30.89 & -0.284 \\
\hline & Tomato & I-2 (clone-2958) & DQ205954.1 & 239 & 26832.0 & 8.33 & 29.82 & -0.295 \\
\hline & Tomato & I-2-Motelle & KR108299.1 & 1266 & 144801.0 & 5.87 & 49.43 & -0.250 \\
\hline & Tomato & I-2 (Heamsona) & FJ843082.1 & 52 & 5710.4 & 4.17 & 88.31 & 0.146 \\
\hline & Tomato & I-2 (Complete cds) & AF118127.1 & 1266 & 144827.1 & 5.87 & 49.50 & -0.252 \\
\hline & Tomato & I-3-SRLK-4 & KP082942.1 & 831 & 91960.3 & 5.62 & 39.57 & -0.145 \\
\hline & Tomato & I-3-SRLK-6 & KP082944.1 & 834 & 93655.9 & 8.22 & 40.16 & -0.185 \\
\hline & Tomato & I-3-SRLK-5 & KP082943.1 & 841 & 94589.8 & 6.97 & 37.97 & -0.177 \\
\hline \multirow{2}{*}{$\begin{array}{l}\text { Fusarium oxysporum } f . \text { sp. } \\
\text { lycopersici }(\mathrm{Fol}) \text { race } 3\end{array}$} & Tomato & I-7 gene & KT185194.1 & 966 & 108155.0 & 5.72 & 33.18 & -0.097 \\
\hline & Tomato & I-7 (Partial) & KT185195.1 & 953 & 106545.2 & 5.49 & 33.85 & -0.091 \\
\hline
\end{tabular}

pI: Isoelectric Point, I.I.: Instability Index, GRAVY- Grand Average of Hydropathicity 
Table.2 Details of five best motifs present in Fusarium resistance genes and their best possible matches

\begin{tabular}{|c|c|c|}
\hline Motif & $\begin{array}{l}\text { Motif } \\
\text { width }\end{array}$ & Best possible match \\
\hline Motif-1 & 39 & CALMMGNEQMSMPCLSTEASWSLFKRHAMENMDPMGHPE \\
\hline Motif-2 & 60 & $\begin{array}{l}\text { LSMDTKGKNLAAVPIVGMGGLGKTTLAKAAYNDERVQKHFVLKA } \\
\text { WFCVSEVYDAFTITKG }\end{array}$ \\
\hline Motif-3 & 39 & QVKLKESLKGKKFVIVLDDVWNENYNEWNDLRNPFVQGD \\
\hline Motif-4 & 39 & LEEVGRQIAAKCKGLPLALKTLAGMLRPKSEIDEWKCIL \\
\hline Motif-5 & 60 & $\begin{array}{l}\text { GKTTLLKTLNNELKENTRDYHVVIMIEVANSETLNVVDMQKIIANRL } \\
\text { GLPWNESETERER }\end{array}$ \\
\hline
\end{tabular}

Table.3 Grouping of cis-regulatory elements in function categories

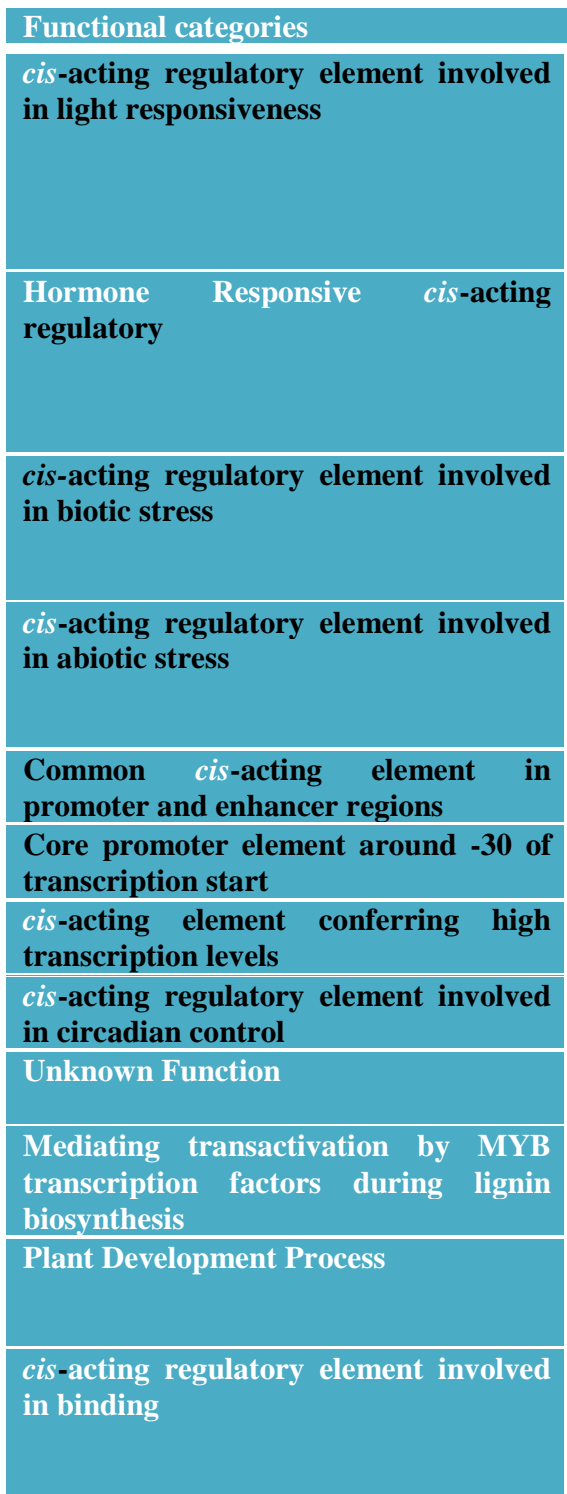

\section{Type of cis-regulatory element}

G-box, Sp1, Box I, TCT-motif, GT1-motif, rbcS-CMA7a, CATT-motif, I-box, GATA-motif, Box 4, AAAC-motif, ACA motif, as-2-box, ATCT-motif, 4clCMA2b, ATCC-motif, CHS-CMA2a, CHS-CMA2a, GA-motif, 3-AF1 binding site, CAG-motif, CGT-motif, CHS-CMA1a, GAG-motif, Gap box, GTGGCmotif, LAMP-element, MRE, TCCC-motif, TGG-motif, AE-box, ACE, L-box, ATC-motif, MNF1

Abscisic acid responsive: ABRE, Motif IIb

Auxin-responsive: TGA-element, AuxRRcore

Ethylene-responsive: ERE

Gibberellin-responsive: P-box, GARE-motif, TATC-box

Salicylic acid responsive: TCA-element

TC-rich repeats (defense and stress responsiveness), Box-W1 (Fungal elicitor), EIRE (Elicitor-responsive), AT-richsequence (Maximal elicitormediated activation), CGTCA-motif (MeJa-responsiveness), TGACG-motif (MeJa-responsiveness)

MBS (drought-inducibility), HSE (heat stress), ARE (anaerobic induction), GC-motif (anoxic specific inducibility), WUN-motif (Wound-responsive) LTR (low-temperature responsiveness), MBSI (flavonoid biosynthetic genes regulation)

CAAT-box

TATA-box

\section{UTR PY-rich stretch}

Circadian

AAGAA-motif, G-box, W-box, AC-I, TCCACCT-motif, GCC box, Y-box, Box E, F-box, Unnamed_1, 2, 3, 4, 8, 11,13 and 16

AC-I

$\mathrm{O}_{2}$-site (Zein metabolism regulation), RY-element (seed-specific regulation), Skn-1_motif (endosperm expression), GCN4_motif (endosperm expression), CCGTCC-box (meristem specific activation)

Protein binding: CCAAT-box

Mybhv1 binding site: CCAAT-box

DNA binding protein : OBP1 site

AT-rich DNA binding protein (ATBP-1): AT-rich element 
Supplementary Table.1 Secondary structure analysis of five Fusarium resistance genes

\begin{tabular}{|c|c|c|c|}
\hline Species & Gene & Secondary structure & Percentage \\
\hline \multirow[t]{8}{*}{ Tomato } & \multirow[t]{4}{*}{ I-2-clone-2942 } & Disordered & $18 \%$ \\
\hline & & Alpha helix & $49 \%$ \\
\hline & & Beta strand & $10 \%$ \\
\hline & & TM helix & $0 \%$ \\
\hline & \multirow[t]{4}{*}{ I-7 } & Disordered & $27 \%$ \\
\hline & & Alpha helix & $20 \%$ \\
\hline & & Beta strand & $23 \%$ \\
\hline & & TM helix & $3 \%$ \\
\hline \multirow{4}{*}{ Banana } & \multirow{4}{*}{ NBS-15 } & Disordered & $16 \%$ \\
\hline & & Alpha helix & $52 \%$ \\
\hline & & Beta strand & $10 \%$ \\
\hline & & TM helix & $0 \%$ \\
\hline \multirow[t]{4}{*}{ Trichodermaharzianum } & \multirow[t]{4}{*}{ Chit-42 } & Disordered & $15 \%$ \\
\hline & & Alpha helix & $34 \%$ \\
\hline & & Beta strand & $18 \%$ \\
\hline & & TM helix & $0 \%$ \\
\hline \multirow[t]{4}{*}{ Soybean (Glycine max) } & \multirow[t]{4}{*}{ Beta-glucanase } & Disordered & $17 \%$ \\
\hline & & Alpha helix & $40 \%$ \\
\hline & & Beta strand & $24 \%$ \\
\hline & & TM helix & $0 \%$ \\
\hline
\end{tabular}

Supplementary Table.2 Ramachandran plot statistics of five different genes

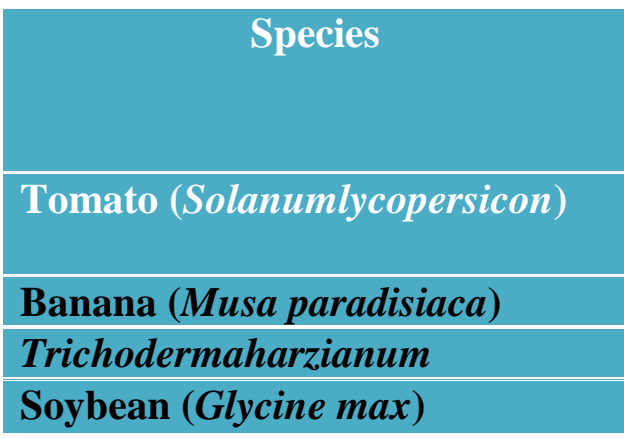

\begin{tabular}{|l|c|c|c|}
\hline \multicolumn{1}{|c|}{ Genes } & \multicolumn{3}{|c|}{ Number of residues Per cent } \\
\cline { 2 - 4 } & $\begin{array}{c}\text { Favoured } \\
\text { region }\end{array}$ & $\begin{array}{c}\text { Allowed } \\
\text { region }\end{array}$ & $\begin{array}{c}\text { Outlier } \\
\text { region }\end{array}$ \\
\hline I-2-clone-2942 & $84.7 \%$ & $8.9 \%$ & $16.4 \%$ \\
\hline I-7 & $76.7 \%$ & $15.2 \%$ & $8.1 \%$ \\
\hline NBS-15 & $85.2 \%$ & $9.7 \%$ & $5.1 \%$ \\
\hline Chit-42 & $97.4 \%$ & $2.1 \%$ & $0.5 \%$ \\
\hline Beta-glucanase & $94.2 \%$ & $5.8 \%$ & $0.0 \%$ \\
\hline
\end{tabular}

Supplementary Table.3 The 3D analysis and Z-score prediction of five Fusarium resistance genes

\begin{tabular}{|l|}
\hline Species \\
\hline Tomato (Solanumlycopersicon) \\
\hline Banana (Musa paradisiaca) \\
\hline Trichodermaharzianum \\
\hline Soybean (Glycine max) \\
\hline
\end{tabular}

\begin{tabular}{|l|c|c|}
\hline Gene & Z-Score & 3D-1D profile >= 0.2 \\
\hline I-2-clone- 2942 & -4.68 & $56.36 \%$ \\
\hline I-7 & -3.30 & $76.09 \%$ \\
\hline NBS-15 & -2.95 & $41.57 \%$ \\
\hline Chit-42 & -7.66 & $89.60 \%$ \\
\hline Beta-glucanase & -7.35 & $95.08 \%$ \\
\hline
\end{tabular}




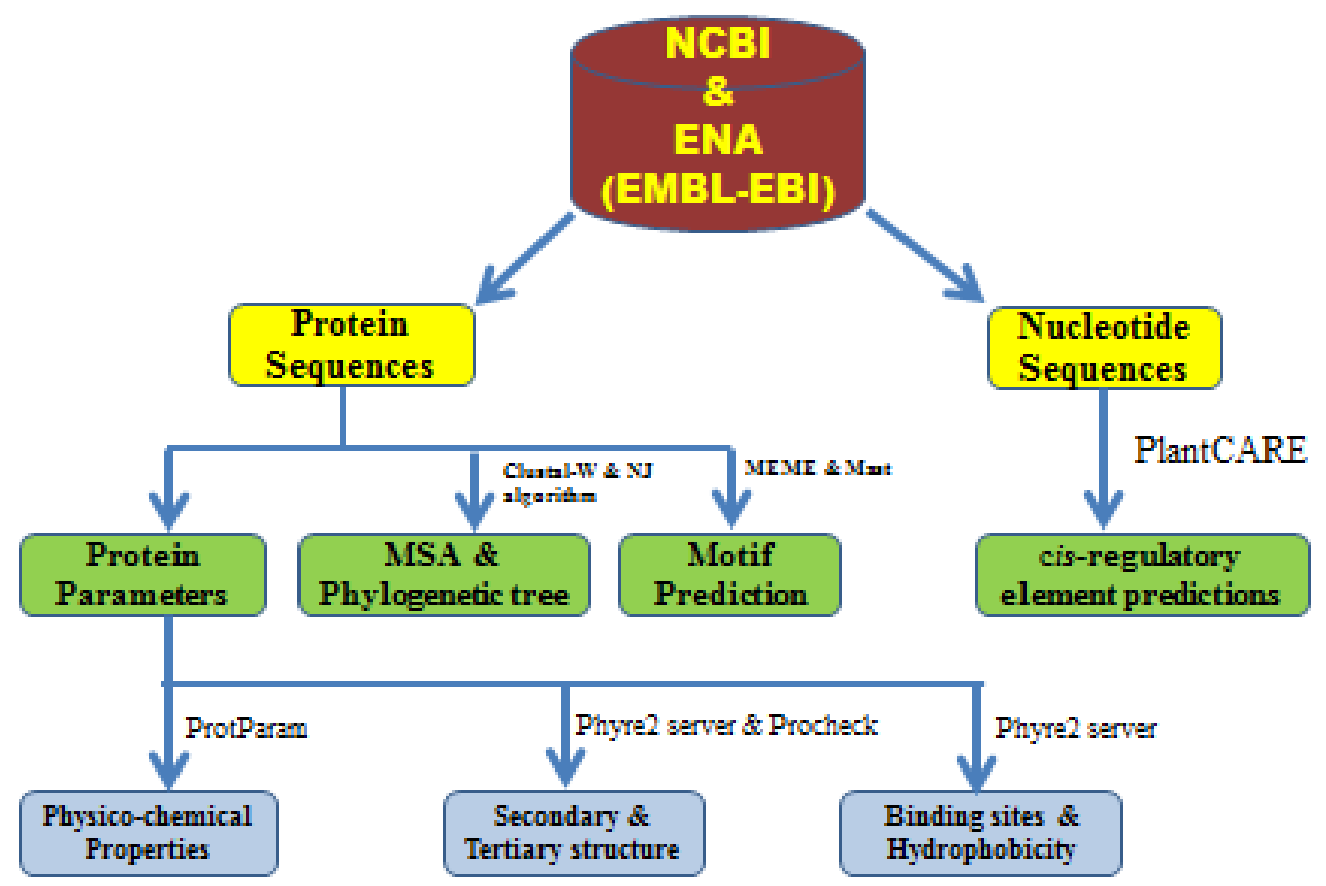

Fig. 1 : Flow chart of in-silico analysis of potential Fusarium resistance genes

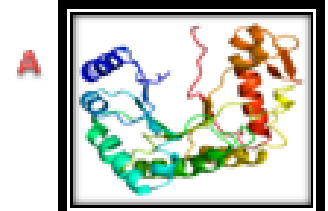

B-glucanase

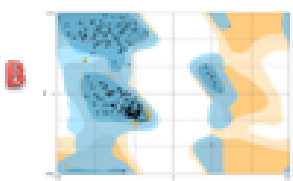

B-glucanase

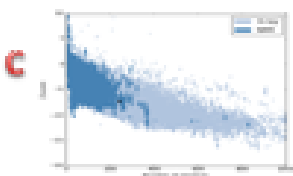

B-glvcanase

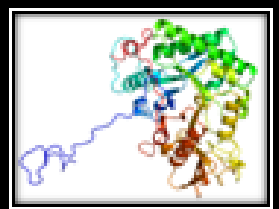

Chit-42 gons

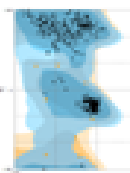

Chit-42 goos

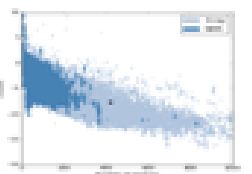

Chit -42 gosos

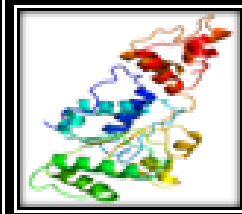

$1-2$ gene

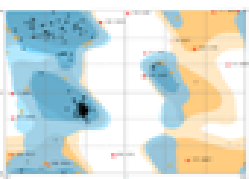

I-2 gene

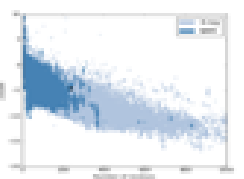

I-2 gene

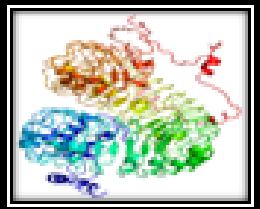

I-7 gene

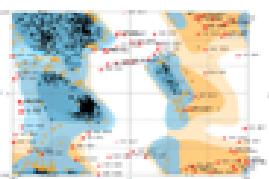

I-7 gene

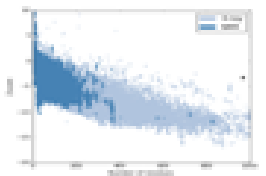

I-7 gene

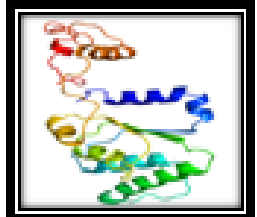

NBS-15 gene

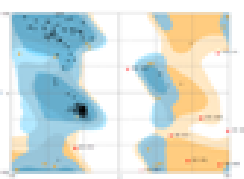

NBS-15 gene

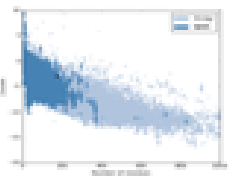

NBS-15 gene

Fig. 2: A) Protein 3D structure predicted by Phyre2server of five Fusarium resistance genes B) Ramchandran plot of five Fusarium resistant gene analyzed through RAMPAGE and the residue are divided into three regions i) Favored region $[\mathbf{\square} \mathbf{\Lambda}, \mathbf{x}]$ ii) Allowed region $[1,4, x]$ and iii) outlier region (white in colour). C) ProSA-web z-scores of five proteins of Fusarium resistance genes (B-glucanase, chit-42, I-2-2942, I-7, and NBS-15) 

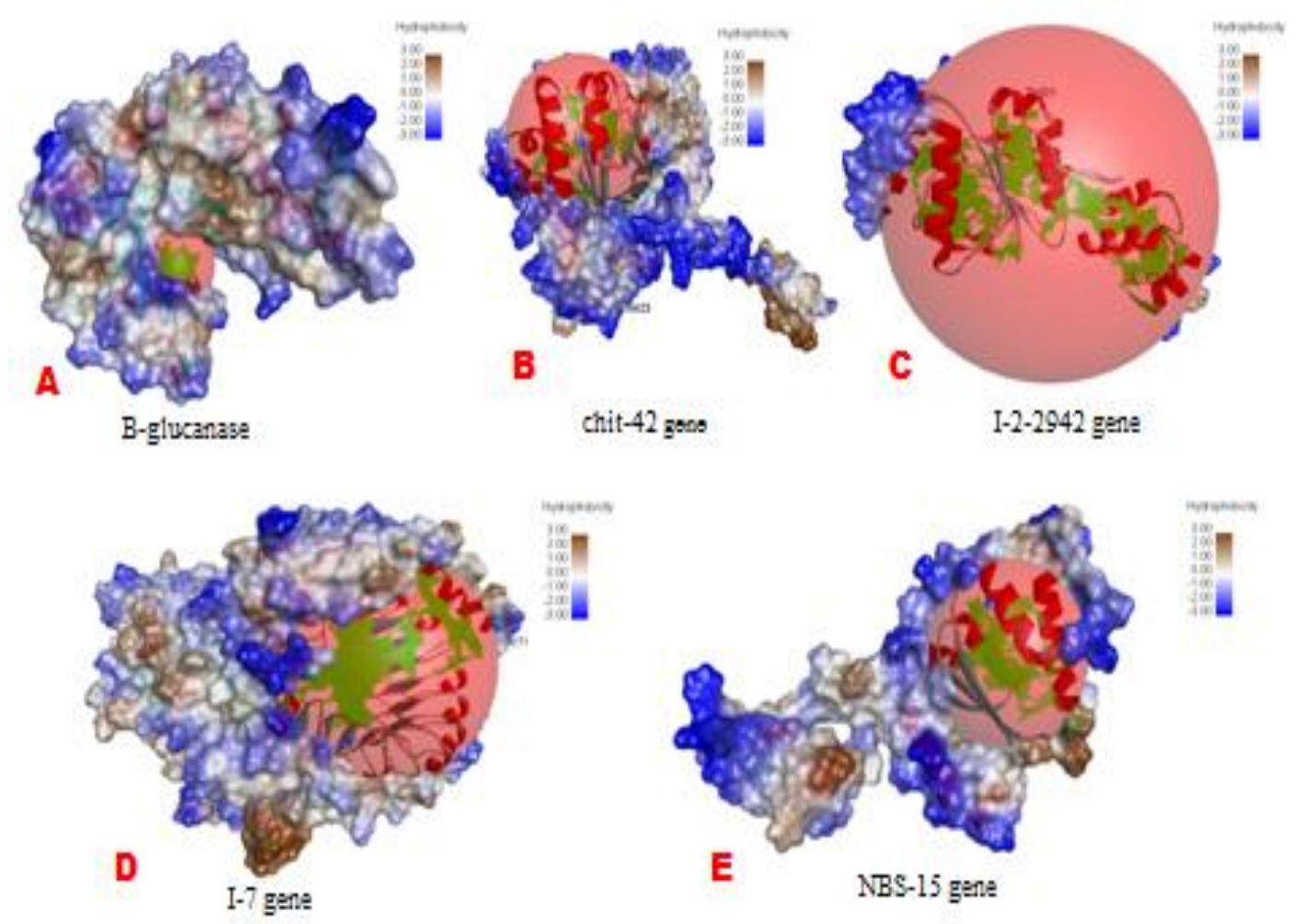

Fig. 3: Binding sites and hydrophobicity analysis in five stable protein sequences of Fusarivon resistance genes : A,) B-glucanase, B) chit-42 gene, C) I-2-2942, D) I-7 gene and E) NBS-15

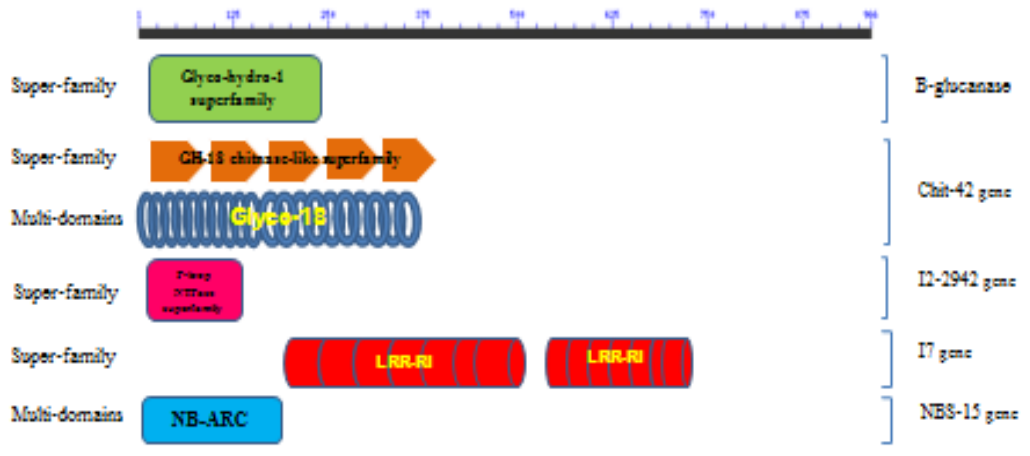

Fig.4: Domain architecture variations in five Fusarium resistance genes. The conserved protein domains were retrieved by using the Conserved Domains Database (CDD) database of NCBI. 

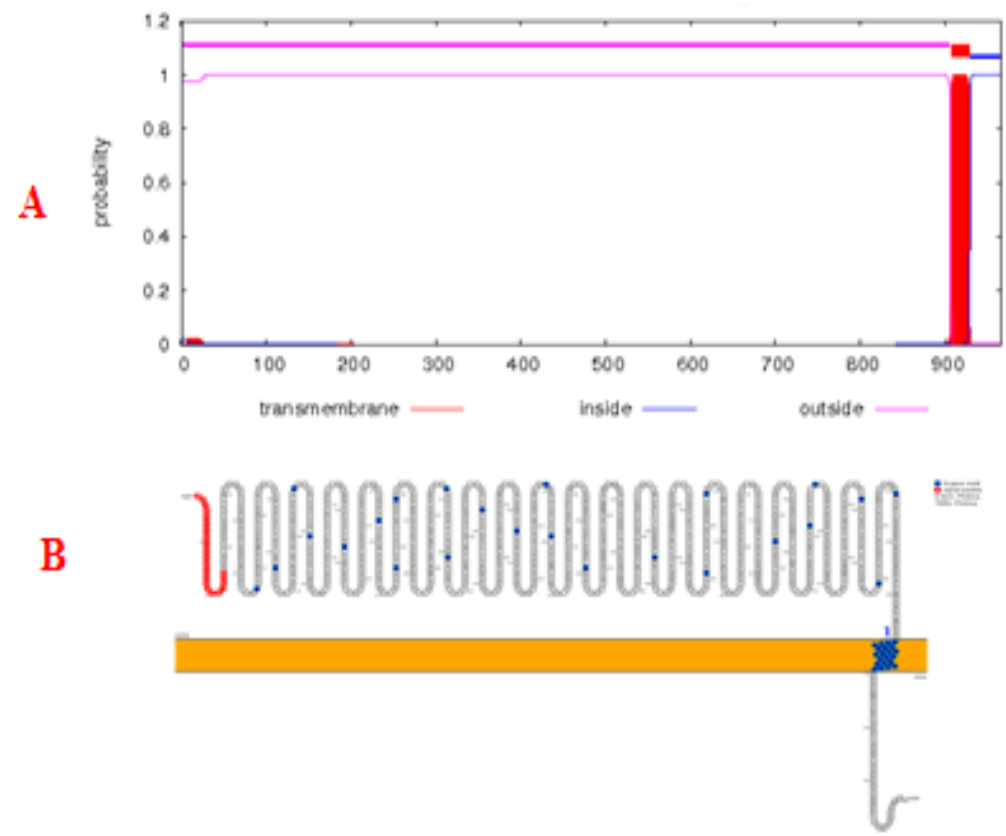

Fig.5: A) Trans-membrane prediction through Trans-membrane Helices Hidden Markov Model (TMHMM Server). B) Visualization of the trans-membrane structure drawn through the plotter tool.

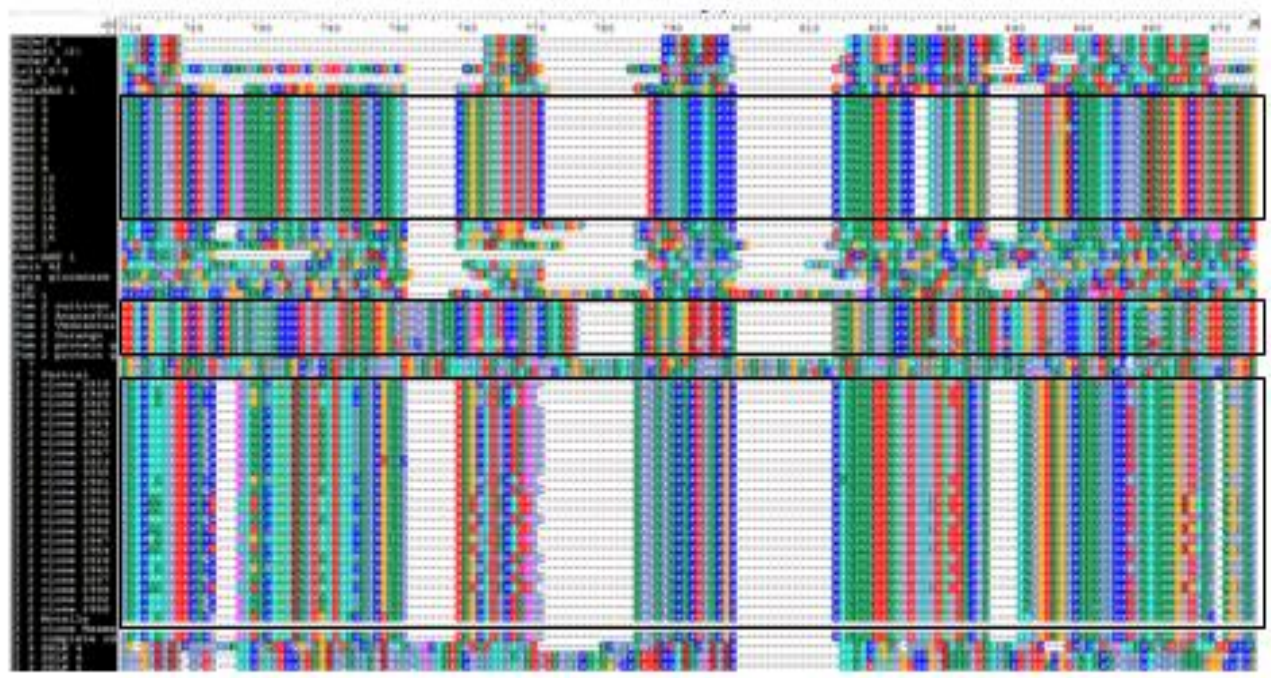

Fig. 6Multiple sequence alignment and sequence comparison of 65 Fusarium resistance genes 


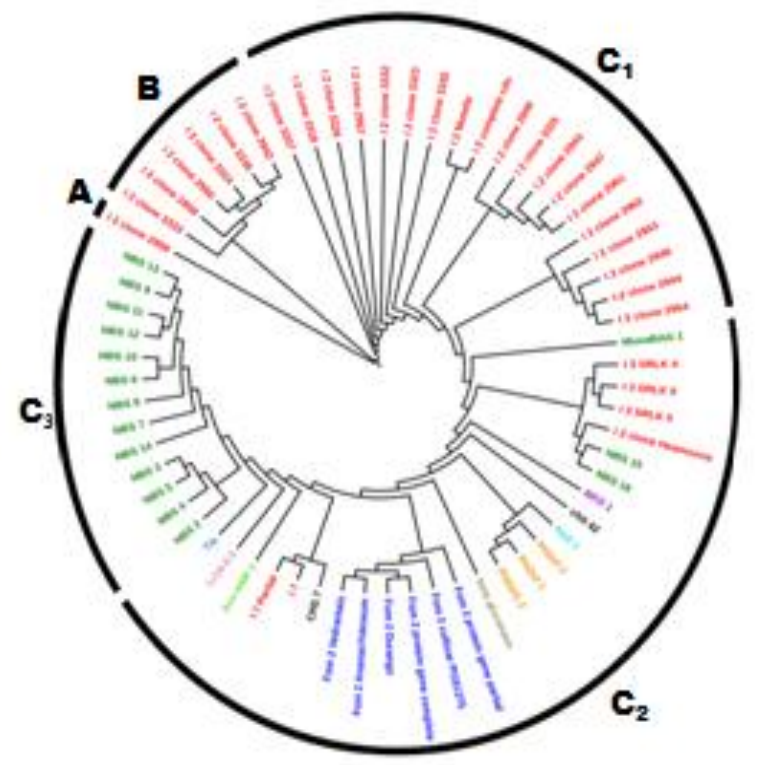

Fig. 7-Neighbor-joining phylogenetic tree based on the ClustalW alignment of Fusarium resistance genes.

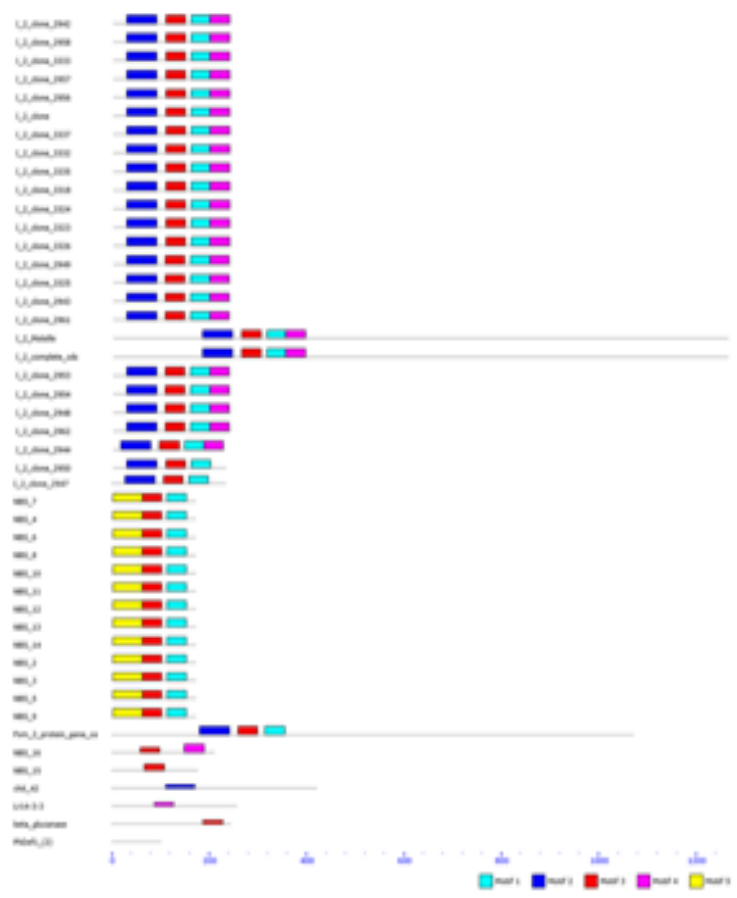

Fig. S1: Protein motif analysis of Fusarium resistance genes having p-value less than 0.0001 


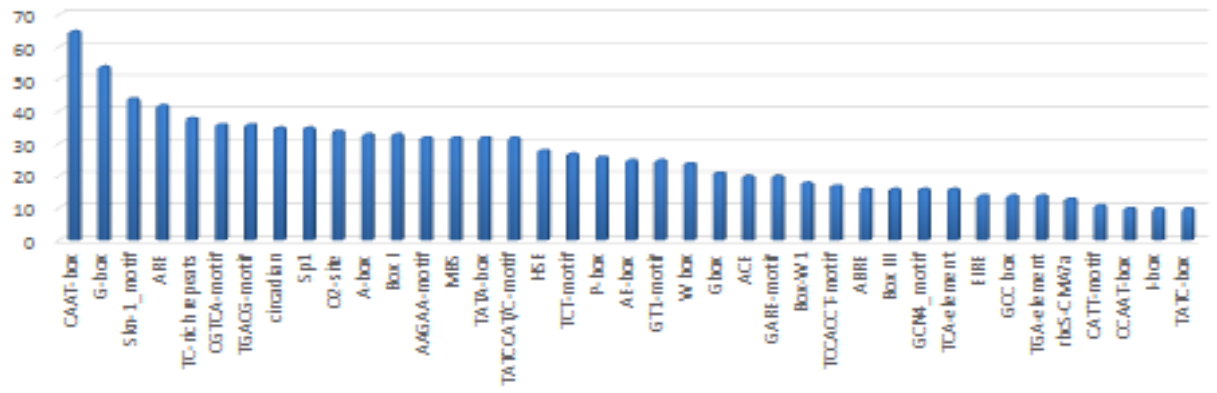

Fig. S2. Cis-regulatory elements (CRE's) having $>10$ repetition among Fusarium resistance genes

Our study revealed that GRAVY score varied from -0.507 (NBS-16) to 0.898 (CHS-7). Similar reports were made earlier by other workers (Zhao and London, 2006; Crasto, 2010; Mallikarjuna et al., 2016).

The alpha helix, beta strand and disordered percentage of secondary structure varied from 20 to $52 \%, 10-24 \%$ and 15 to $27 \%$ respectively. This information of secondary structure of protein will be helpful in understanding both the mechanisms of folding and the biological activity of proteins (Sivan et al., 2007). The 3D structure predicted the arrangement of secondary structures as well as their side chains into three-dimensional space. The $\mathrm{Z}$ score of five stable Fusarium resistance genes (I-2, I-7, NBS-15, chit-42 and B-glucanase) were -7.35, -7.66, -4.68, 3.30 and -2.95 respectively. The negative value of $Z$-score indicated that these structures are reliable. Similar negative value of $\mathrm{Z}$ score was estimated in $\mathrm{AC} 1$ proteins of begomovirus strains (Prajapat et al., 2007) and chitinase gene family in wheat (Mishra et al., 2015).

Protein binding site is region in a protein on which specific molecules/ions attach to form a chemical bond. The knowledge of hydrophobicity will be helpful to have an idea regarding protein folding, prediction of transmembrane sequences and water-protein-lipid interaction. In the current study, the protein binding sites and hydrophobicity level observed in beta-glucanase, I-2-clone-2942, I7, chit-42 and NBS-15 suggested that the distribution pattern in these five genes for binding site is more, while hydrophobicity is very low to low. In proteins, binding sites are more active sites which are mainly due to hydrophobic nature and also play an important role in the interaction specificity (Labute and Santavy, 2007; Stank et al., 2016). It is necessary to understand the distribution pattern of hydrophobicity in protein sequences and structures because hydrophobicity plays an important role in development of protein structures (Sandelin, 2004). The information on protein binding sites and receptor functionalities in horticultural crops is still lacking. Our findings on hydrophobicity of protein sequences show potential to find the crystallographic determinations of each binding sites and offers possibilities for developing varieties resistant to Fusarium diseases in different crops. Protein domain dynamics play crucial roles for molecular recognition and signalling processes in cells.

The GH18 (Glycoside Hydrolase18) domain was found in B-glucanase gene, while NBARC domain was found in NBS-15 gene. GH18, a multigene family of chitinases plays various roles in embryonic development and 
allergic inflammation (Huang et al., 2012). In the disease resistance genes or proteins, the NB-ARC acts as molecular switch to help the plant against biotic and abiotic stresses (Pal et al., 2007; Van et al., 2008). In our results, two of the genes (chit-42 and NBS-15) had multidomain proteins. These multiple domain proteins are highly stable and have benefits in terms of folding compared to single domain proteins in the cell (Bhaskara et al., 2011). The conserved domains namely GH18, NBARC, LRR-RI,P-loop NTPase superfamily andGlyco-18 present in resistance genes are independently stable sequences which can be used to develop chimeric proteins through genetic engineering for crop improvement. In our results, trans-membrane helix was present in I-7 gene; while it was absent in rest of four genes. Trans-membrane proteins in the resistance genes regulate the information and other different substances from inside and outside of the cell and are actively involved in a various other biological processes (Reynolds et al., 2008).

Multiple sequence alignment (MSA) is becoming powerful tool in plant science for estimating phylogenetic trees, illuminating functionally important regions, structure prediction of proteins (secondary and tertiary structure), protein function, structure of RNAs (Kemena and Notredame, 2009), biological function analysis and performing the task of next-generation sequencing (Ortuno et al., 2013). In the present study, protein sequences of 65 Fusarium resistance genes were used to find out the homologous sequences and multiple sequence alignment, and the conserved regions obtained will be helpful in knowing the binding sites, active sites and development of molecular makers.

In-silico motif analysis of 65 Fusarium resistance genes revealed that motif- 3 was present in 43 genes followed by motif- 1 in 40 genes. The gene NBS-15, chit-42, Lr14-3-3 and beta-glucanase had one motif; NBS-16 gene had two motifs. The statistical significance of motif prediction was correlated with biological significance, indicating a valuable reason for the motifs analysis as also reported earlier by Zhang et al., (2009). Motifs information can be used for developing resistance genes and makers, to perform clustering (Broin et al., 2015), gene expression analysis study (Jensen et al., 2005, Huber and Bulyk, 2006) and discovery of homology relations (Stewart, 2016), family classification (Blekas et al., 2005; Eser et al., 2013), discovery of sub-families in large protein families (Leonardi and Galves, 2005) and new signalling pathways ( $\mathrm{Ma}$ et al., 2013).

Phylogenetic tree results were in agreement with the results of conserved motif analysis. The phylogenetic analysis of Fusarium resistance genes presented in group A showed more similar conserved motif pattern with group $\mathrm{B}$, followed by subgroup $\mathrm{C} 1$ and $\mathrm{C} 3$ (Fig. 7). Evolutionary forces probably caused these changes during evolutionary processes. Subgroup C2 was unique as compared to other groups and subgroups which could be due to some genomic forces (insertion, deletion etc.) which might affect the different Fusarium resistance gene structures.

We observed various cis-regulatory elements i.e. TC-rich repeats, Box-W1, EIRE, AT-rich sequence, CGTCA-motif; TGACG-motif which involved in crucial roles against Fusarium induced diseases in various horticultural crops. The spatial and temporal differences in gene expression levels of an organism are the result of interactions between DNA, RNA and protein. DNA cisregulatory elements consist of promoters, enhancers and insulators which play important role in gene regulation process (Fiedler and Rehmsmeier, 2006; Ibraheem et al., 2010; Himani et al., 2014). To understand 
the gene regulation process and the development process of organisms, the knowledge of cis-regulatory elements is indispensable. Our studies showed that BoxW1 cis-regulatory element is Fusarium elicitor responsive and provides insights in the evolution of Fusarium resistance genes.

The identification of these CRE and their CREs across species will allow an understanding of the diversity, distribution and evolutionary relationships of these genes (Wittkopp, and Kalay, 2012; Lemmon et al., 2014; Hernandez-Garcia, and Finer, 2014).

In-silico analysis revealed the homology of 65 Fusarium resistance genes. Resistance genes can be used to improve plant resistance through genome editing and gene silencing strategies. The physicochemical properties of Fusarium resistance genes can be used for identification of homologs in different plant genomes.

Knowledge of phylogenetic trees, cis-acting elements and motif prediction generated from this study will give better understanding of the transcriptional gene regulation system. It is essential to decipher the expression of these resistance genes, cis-regulatory elements and markers in economically important horticultural crops to improve disease resistance. The 3D structure of 5 stable Fusarium genes can be effectively used for in silico docking study for development of potential ligand molecules against Fusarium infection. Our study also identified potential candidate genes. The marker developed from the candidate genes will be useful to develop highly resistance genotypes.

\section{Acknowledgement}

The financial assistance provided by Director, ICAR-IARI, New Delhi, India for conducting the studies is gratefully acknowledged.

\section{References}

Agrawal, A.A., 2011. Current trends in the evolutionary ecology of plant defence. Funct. Ecol. 25:420-32.

Agrawal, A.A., Fishbein, M., 2008. Phylogenetic escalation and decline of plant defense strategies. Proc. Natl. Acad. Sci. U.S.A..105:10057-60.

Agrawal, A.A., Fishbein, M., Halitschke, R., Hastings, A.P., Rabosky DL, Rasmann S., 2009. Evidence for adaptive radiation from a phylogenetic study of plant defenses. Proc. Natl. Acad. Sci. U.S.A. 106:18067-72.

Azam, S., Munir, A., Khan, M.S., Fazal, S., Mehmood, A., 2017. In-Silico Identification of Novel Resistant Genes for Fungal Pathogen Fusarium oxysporum f. sp. cubense Race 4: Causative Agent of Banana Vascular Wilt Disease. J. Plant Biochem. Physiol. Pp. 5-2.

Bentley, A.R., Cromey, M.G., Farrokhi-Nejad, R., Leslie, J.F., Summerell, B.A., Burgess, L.W., 2006. Fusarium crown and root rot pathogens associated with wheat and grass stem bases on the South Island of New Zealand. Australas. Plant Pathol. 35: 495-502.

Bhaskara, R.M., Srinivasan, N., 2011. Stability of domain structures in multi-domain proteins. Sci. Rep.1:40.

Bhati, J., Chaduvula, K.P., Rai, A., Gaikwad, K., Soma, M., S., 2016. In-Silico Prediction and Functional Analysis of Salt Stress Responsive Genes in Rice (Oryza sativa). J. Rice Res. 4: 2.

Blekas, K., Fotiadis, D.I., Likas, A., 2005. Motif-based protein sequence classification using neural networks. J. Comput Biol. 12:64-82.

Bockus, W.W., Bowden, R.L., Hunger, R.M., Morrill, W.L., Murray, T.D., Smiley, R.W., 2007. Compendium of Wheat Diseases and Insects, 3rd Edition. APS Press, St. Paul, MN.

Broin, P.Ó., Smith, T.J., Golden, A.A., 2015. Alignment-free clustering of transcription 
factor binding motifs using a genetic-kmedoids approach. BMC bioinformatics.16:22.

Chakraborty, S., Newton, A.C., 2011. Climate change, plant diseases and food security: an overview. Plant Pathol. 60:2-14.

Crasto, C.J., 2010. Hydrophobicity profiles in G protein-coupled receptor transmembrane helical domains. J Receptor Ligand Channel Res..123.

Dutt, S., Singh, V.K., Marla, S.S., Kumar, A., 2010. In silico analysis of sequential, structural and functional diversity of wheat cystatins and its implication in plant defense. Genomics, proteomics \& bioinformatics, 8: 42-56.

Eser, E.M., Arslan, B.R., Sezerman, U.O., 2013. Classification of cohesin family using class specific motifs. In Health Informatics and Bioinformatics (HIBIT), $8^{\text {th }}$ International Symposium on 2013 Sep 25. IEEE

Fiedler, T., Rehmsmeier, M., 2006. jPREdictor: a versatile tool for the prediction of cisregulatory elements. Nucleic Acids Res..34:546-550.

Gao, X., Song, P.X., 2010. Composite likelihood Bayesian information criteria for model selection in high-dimensional data.J. Amer. Statist. Assoc. 105:15311540.

Garcia-Moreno, B. 2009. Adaptations of proteins to cellular and subcellular pH.J. Biol.8:98.

Gaucher, E.A., Kratzer, J.T., Randall, R.N., 2010. Deep phylogeny how a tree can help characterize early life on Earth. Cold Spring Harb. Perspect. Biol.2:a002238.

Hernandez-Garcia, C.M, Finer, J.J., 2014. Identification and validation of promoters and cis-acting regulatory elements. Plant Sci.217:109-19.

Himani, S., Sonia, S., Sneh, N., Rekha, M., Indu, S., Ravish, C., 2014. Computational analysis of cis-acting regulatory elements in 5'regulatory regions of sucrose transporter gene families in wheat and Arabidopsis. Res. J. Biotechnol.9:4.
Hu, B., Jin, J., Guo, A.Y., Zhang, H., Luo, J., Gao, G., 2014. GSDS 2.0: an upgraded gene feature visualization server. Bioinformatics. 817.

Huang, Q.S., Xie, X.L., Liang, G., Gong, F., Wang, Y., Wei, X.Q., Wang, Q., Ji, Z.L., Chen, Q.X., 2012. The GH18 family of chitinases: their domain architectures, functions and evolutions. Glycobiology.22:23-34.

Huber, B.R., Bulyk, M.L., 2006. Meta-analysis discovery of tissue-specific DNA sequence motifs from mammalian gene expression data. BMC Bioinformatics. $7: 229$.

Ibraheem, O., Botha, C.E., Bradley, G., 2010. In silico analysis of cis-acting regulatory elements in $5^{\prime}$ regulatory regions of sucrose transporter gene families in rice (Oryzasativa Japonica) and Arabidopsis thaliana. Res. J.Biotechnol.34:268-83.

Jensen, S.T., Shen, L., Liu, J.S., 2005. Combining phylogenetic motif discovery and motif clustering to predict coregulated genes. Bioinformatics.21:38329.

Johnson, L.S., Eddy, S.R., Portugaly, E., 2010. Hidden Markov model speed heuristic and iterative HMM search procedure. BMC bioinformatics.11:431.

Joshi, R.K., Nayak, S., 2013. Perspectives of genomic diversification and molecular recombination towards R-gene evolution in plants. Physiol. Mol. Biol. Plants.19:19.

Kemena, C., Notredame, C., 2009. Upcoming challenges for multiple sequence alignment methods in the high-throughput era. Bioinformatics.25:2455-65.

Krogh, A., Larsson, B., Von Heijne, G., Sonnhammer, E. L., 2001. Predicting transmembrane protein topology with a hidden Markov model: application to complete genomes. J.Mol.Biol. 305: 567580.

Labute, P., Santavy, M., 2007. Locating binding sites in protein structures. J. Chem. Comput. Group. 
Lemmon, Z.H., Bukowski, R., Sun, Q., Doebley, J.F., 2014. The role of cis regulatory evolution in maize domestication. PLoS Genet.10:e1004745.

Leonardi, F., Galves, A., 2005. Sequence motif identification and protein family classification using probabilistic trees. In Brazilian Symposium on Bioinformatics.190-193. Springer Berlin Heidelberg.

Lescot, M., Dehais, P., Thijs, G., Marchal, K., Moreau, Y., Van de Peer, Y., Rouze, P., Rombauts, S., 2002. PlantCARE, a database of plant cis-acting regulatory elements and a portal to tools for in silico analysis of promoter sequences. Nucleic Acids Res.30:325-7.

Lovell, S.C., Davis, I,W., Arendall, W.B., de Bakker, P.I., Word, J.M., Prisant, M.G., Richardson, J.S., Richardson, D.C.,2003. Structure validation by $\mathrm{C} \alpha$ geometry: $\phi, \psi$ and $\mathrm{C} \beta$ deviation. Proteins: Struct. Funct.Bioinf.50: 437-450.

Luthy, R., Bowie, J.U., Eisenberg, D., 1992. Assessment of protein models with threedimensional profiles. Nature.356:83.

Ma, S., Shah, S., Bohnert, H.J., Snyder, M., Dinesh-Kumar, S.P., 2013. Incorporating motif analysis into gene co-expression networks reveals novel modular expression pattern and new signaling pathways. PLoS Genet.9:e1003840.

Mallikarjuna, M.G., Nepolean, T., Mittal, S., Hossain, F., Bhat, J.S., Manjaiah, K. M. Marla, S., Mithra, A.C., Agrawal, P.K., Rao, A.R., Gupta, H.S.,2016. In-silico characterisation and comparative mapping of yellow stripe like transporters in five grass species. Indian J. Agric. Sci.86:621-627

Marchler-Bauer, A., Derbyshire, M.K., Gonzales, N.R., Lu, S., Chitsaz, F., Geer, L.Y., Geer, R.C., He, J., Gwadz, M., Hurwitz, D.I, Lanczycki, C.J., 2014.CDD: NCBI's conserved domain database. Nucleic Acids Res.222-226.

Mishra, A.K., Pandey, B., Tyagi, C., Chakraborty, O., Kumar, A., Jain, A.K., 2015. Structural and functional analysis of chitinase gene family in wheat (Triticum aestivum). Indian J. Biochem. Biophys.52:169-78

Nakashima, K., Ito, Y., Yamaguchi-Shinozaki, K., 2009. Transcriptional regulatory networks in response to abiotic stresses in Arabidopsis and grasses. Plant Physiol.149:88-95.

Nelson, P.E., Dignani, M.C., Anaissie, E.J., 1994. Taxonomy, biology, and clinical aspects of Fusarium species. Clin. Microbiol.Rev. 7: 479-504.

Nottensteiner, M., 2015. Molecular Characterization of Retroelement Encoded ROPIP1 as Virulence Effector of Blumeriagraminis $f . \quad s p$. hordei (Doctoral dissertation, Dissertation, Munchen, Technische Universitat Munchen..

Omasits, U., Ahrens, C.H., Müller, S., Wollscheid, B., 2013. Protter: interactive protein feature visualization and integration with experimental proteomic data. Bioinformatics.btt607.

Ortuno, F.M., Valenzuela, O., Pomares, H., Rojas, F., Florido, J.P., Urquiza, J.M., Rojas, I., 2013. Predicting the accuracy of multiple sequence alignment algorithms by using computational intelligent techniques. Nucleic Acids Res.41:e26.

Pal, A., Chakrabarti, A., Basak, J., 2007. New motifs within the NB-ARC domain of $\mathrm{R}$ proteins: Probable mechanisms of integration of geminiviral signatures within the host species of Fabaceae family and implications in conferring disease resistance. J. Theor. Biol.246:56473.

Prajapat, R., Marwal, A., Gaur, R.K. 2014. Recognition of Errors in the Refinement and Validation of Three-Dimensional Structures of AC1 Proteins of Begomovirus Strains by Using ProSAWeb. J. Viruses.

Reynolds, S.M., Kall, L., Riffle, M.E., Bilmes, J.A., Noble, W.S., 2008. Transmembrane topology and signal peptide prediction using dynamic bayesian networks. PLoS Comput. Biol. 4:e1000213. 
Ronsted, N., Symonds, M.R., Birkholm, T., Christensen, S.B., Meerow, A.W., Molander, M., Molgaard, P., Petersen, G., Rasmussen, N., Van, Staden, J., Stafford, G.I., 2012. Can phylogeny predict chemical diversity and potential medicinal activity of plants? A case study of Amaryllidaceae. BMC Evol. Biol.12:182

Sandelin, E., 2004. On hydrophobicity and conformational specificity in proteins. Biophys. J.86:23-30.

Saremi, H., Burgess, L.W., 2010. Effect of soil temperature on distribution and population dynamics of Fusarium species. J. Agric. Sci.Tech. 2:119-125.

Sivan, S., Filo, O., Siegelmann, H., 2007. Application of expert networks for predicting proteins secondary structure. Biomol. Eng.24:237-243

Stank, A., Kokh, D.B, Fuller JC, Wade RC. 2016. Protein Binding Pocket Dynamics. Acc. Chem. Res.49:809-15.

Stewart, Jr. C.N., 2016. Plant biotechnology and genetics: principles, techniques, and applications. John Wiley \& Sons.432

Talley, K., Alexov, E., 2010. On the $\mathrm{pH}$ - optimum of activity and stability of proteins. Proteins: Struct. Funct.Bioinf.78:2699-706.

Tamura, K., Stecher, G., Peterson, D., Filipski, A., Kumar, S., 2013. MEGA6: molecular evolutionary genetics analysis version 6.0. Mol. Biol. Evol.30:2725-9.

Van den, B. E., Hofberger, J.A., Schranz, M. E., 2016. Flower power and the mustard bomb: Comparative analysis of gene and genome duplications in glucosinolate biosynthetic pathway evolution in Cleomaceae and Brassicaceae. Am. J. Bot.103:1212-22.

Van, O.G., Mayr, G., Kasiem, M.M., Albrecht, M., Cornelissen, B.J., Takken, F.L., 2008. Structure-function analysis of the NBARC domain of plant disease resistance proteins. J. Exp. Bot.59:1383-97.

Werner, G.D, Cornwell, W.K, Sprent, J.I, Kattge, J, Kiers, E.T., 2014. A single evolutionary innovation drives the deep evolution of symbiotic N2-fixation in angiosperms. Nat. Commun.5

Wiederstein, M., Sippl, M.J., 2007. ProSA-web: interactive web service for the recognition of errors in three-dimensional structures of proteins. Nucleic Acids Res.35:407410.

Wittkopp, P.J., Kalay, G., 2012. Cis-regulatory elements: molecular mechanisms and evolutionary processes underlying divergence. Nature Rev. Genet.13:59-69.

Zhang, S., Su, W., Yang, J. 2009. ARCS-Motif: discovering correlated motifs from unaligned biological sequences. Bioinformatics.25:183-189.

Zhao, G., London, E., 2006. An amino acid "transmembrane tendency" scale that approaches the theoretical limit to accuracy for prediction of transmembrane helices: relationship to biological hydrophobicity. Prot. Sci.; 15: 19872001.

\section{How to cite this article:}

Ashok Yadav, Usha Kalidindi, Pawan Kumar Jayaswal, Shikha Mittal and Nepolean Thirunavukkarasu. 2018. Molecular Characterization and Evolutionary Analysis of Potential Fusarium Resistant Genes for Crop Improvement. Int.J.Curr.Microbiol.App.Sci. 7(02): 30523070. doi: https://doi.org/10.20546/ijcmas.2018.702.369 